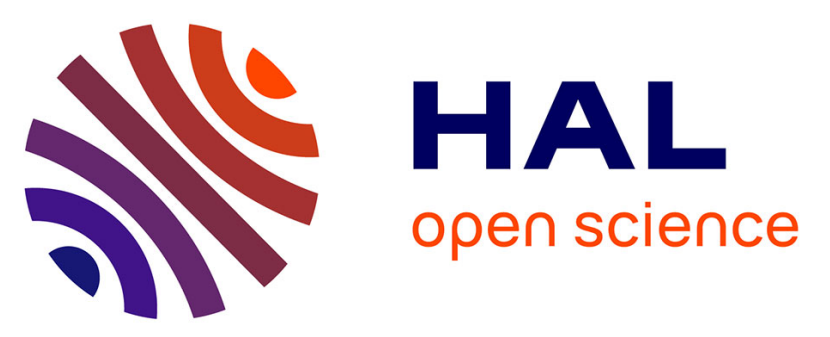

\title{
BK-polyomavirus seroreactivity measured in kidney donors is strongly associated with incidence of viremia and nephropathy in their recipients
}

H.F. Wunderink, E. van Der Meijden, C.S. van Der Blij-de Brouwer, Antoine Touzé, M.J. Mallat, G.W. Haasnoot, E.W. van Zwet, E.C.J. Claas, J.W. de Fijter, A.C.M. Kroes, et al.

\section{To cite this version:}

H.F. Wunderink, E. van Der Meijden, C.S. van Der Blij-de Brouwer, Antoine Touzé, M.J. Mallat, et al.. BK-polyomavirus seroreactivity measured in kidney donors is strongly associated with incidence of viremia and nephropathy in their recipients. 18. Annual Meeting of the European Society for Clinical Virology, Sep 2015, Édimbourg, United Kingdom. Academic Press - Elsevier, Journal of Clinical Virology, 70, 2015, Journal of Clinical Virology. 10.1016/j.jcv.2015.07.051 . hal-01239515

\section{HAL Id: hal-01239515 \\ https://hal.science/hal-01239515}

Submitted on 3 Jun 2020

HAL is a multi-disciplinary open access archive for the deposit and dissemination of scientific research documents, whether they are published or not. The documents may come from teaching and research institutions in France or abroad, or from public or private research centers.
L'archive ouverte pluridisciplinaire HAL, est destinée au dépôt et à la diffusion de documents scientifiques de niveau recherche, publiés ou non, émanant des établissements d'enseignement et de recherche français ou étrangers, des laboratoires publics ou privés. 
seen with cidofovir. However, randomized controlled studies are required to confirm this impression.

http://dx.doi.org/10.1016/j.jcv.2015.07.049

\section{Abstract No: 1766}

\section{Presentation at ESCV 2015: Oral 40 \\ Fatal disseminated varicella zoster infection following zoster vaccination in an immunocompromised patient}

E. Costa ${ }^{1, *}$, J. Buxton ${ }^{2}$, J. Brown ${ }^{3}$, K. Templeton ${ }^{1}$, J. Breuer ${ }^{3}$, I. Johannessen ${ }^{1}$

${ }^{1}$ Department of Laboratory Medicine, Edinburgh Royal Infirmary, UK

2 Department of Clinical and Laboratory Haematology, Borders General Hospital, UK

${ }^{3}$ Virology Department, Great Ormond Street Hospital for Children, UK

Background: In November 2014, a 79 year-old gentleman was admitted to a Scottish hospital with a temperature of $41^{\circ} \mathrm{C}$ and a widespread vesicular rash. The patient finished immunosuppressive treatment for his chronic lymphocytic leukaemia in April 2014 and received the zoster vaccine as part of the regular UK immunisation catch up programme against shingles in October 2014. Intravenous (iv) treatment with piperacilin/tazobactam, gentamicin and aciclovir $(10 \mathrm{mg} / \mathrm{kg}$ tds $)$ was started and he initially remained stable with no evidence of systemic involvement. On day 6 after hospitalization, he abruptly developed respiratory and renal failure that required transfer to the Intesive Therapy Unit (ITU). Aciclovir dose was increased $(20 \mathrm{mg} / \mathrm{kg}$ tds $)$ and a total of 5 doses of human normal immunoglobulin were administered $(400 \mathrm{mg} / \mathrm{kg})$. Brochoalvelar lavage (BAL), vesicle fluid and plasma were positive by polymerase chain reaction (PCR) for VZV. Despite becoming VZV negative on BAL, plasma and extubated by day 12 in the ITU, the patient subsequently developed multi-organ failure and died 25 days after hospitalization.

Methods: VZV Oka vaccine strain was detected in vesicle fluid using a real-time PCR assay that targets SNP 108111 in a $174 \mathrm{bp}$ region of ORF 62. SNP 108111 has been show to differentiate VZV vaccine and wild-type sequences. Briefly, reactions consisted of $0.7 \mu \mathrm{M}$ each primer (VZV-F, 5' CGAAACAAACTCACGACTCTT; VZV-R, 5'GATACCCGCCCAAGGAAA) and $1.4 \mu \mathrm{M}$ each probe (WT-Pr, 5' JOE TTTCTCcACtGGgCTGTCA; Oka-Pr, 5'FAM - TTTcTCcACcGGgCTGTCA, where DNA nucleotides are denoted in upper case, LNA nucleotides in lower case and the LNA nucleotide complementary to SNP 108111 is underlined), Quantifast Multiplex PCR mastermix (Qiagen), $5 \mu \mathrm{l}$ purified DNA and water to make a $25 \mu \mathrm{l}$ reaction volume. Cycling on an ABI 7500 Fast consisted of $95^{\circ} \mathrm{C}$ for 5 minutes followed by 45 cycles of $95^{\circ} \mathrm{C}$ for 30 seconds and $60^{\circ} \mathrm{C}$ for 30 seconds.

Results: The test results obtained in the present case demonstrate the possibility of the zoster vaccine causing widespread infection in the immunocompromised. To the best of our knowledge, this is the first lethal case of disseminated varicella zoster following vaccination in the UK.

Conclusion: There is a lack of data-driven recommendations in the current guidelines for zoster vaccine in the imunocompromised setting. Careful review of the individual patient and their level of immunosuppression is required before zoster vaccination.

http://dx.doi.org/10.1016/j.jcv.2015.07.050
Abstract No: 1688

Presentation at ESCV 2015: Oral 41

BK-polyomavirus seroreactivity measured in kidney donors is strongly associated with incidence of viremia and nephropathy in their recipients

H.F. Wunderink ${ }^{1, *}$, E. van der Meijden ${ }^{1}$, C.S. van der Blij-de Brouwer ${ }^{1}$, A. Touzé ${ }^{2}$, M.J. Mallat ${ }^{3}$, G.W. Haasnoot ${ }^{4}$, E.W. van Zwet $^{5}$, E.C.J. Claas ${ }^{1}$, J.W. de Fijter ${ }^{3}$, A.C.M. Kroes ${ }^{1}$, F.H.J. Claas ${ }^{4}$, J.I. Rotmans $^{3}$, M.C.W. Feltkamp ${ }^{1}$

${ }^{1}$ Department of Medical Microbiology, Leiden University Medical Center, Leiden, The Netherlands

${ }^{2}$ UMR INRA ISP1282, Université François Rabelais,

Tours, France

${ }^{3}$ Department of Nephrology, Leiden University

Medical Center, Leiden, The Netherlands

${ }^{4}$ Department of Immunohematology and Blood

Transfusion, Leiden University Medical Center,

Leiden, The Netherlands

${ }^{5}$ Department of Medical Statistics and

Bioinformatics, Leiden University Medical Center,

Leiden, The Netherlands

Background: Solid organ transplant recipients frequently develop symptoms of previously latent viral infections. The origin, endogenously reactivated or donor organ-derived, and severity of such infections is often difficult to predict. In the case of BK polyomavirus (BKV)-induced nephropathy, which develops in a subset of kidney transplant (KTx) recipients and causes inflammation and allograft loss, donor origin of infection is suspected. Since it has been suggested that BKV-seroresponsiveness reflects BKV-(re)activity, we hypothesized that donor BKV seroresponses correlate with infection in the KTx recipients, and can be used as a predictor of BKV-related disease.

Methods: A retrospective cohort of 407 living KTx donorrecipient pairs was formed, transplanted between 2003 and 2013 at the Leiden University Medical Center. Pre-KTx serum samples from donors and recipients were tested for the presence and intensity of BKV viral capsid protein 1 (VP1)-directed seroresponses by Luminex. The BKV VP1-IgG seroresponses were correlated with recipient BKV-loads determined after transplantation and compared with other described risk factors for BKV-infection.

Results: During one year of follow-up after KTx, BKV-viremia was observed in $27 \%$ of recipients. Baseline BKV-seroprevalence among donors (96\%) and recipients (95\%) was high and not correlated with recipient viremia. However, a strong association was observed between strength of pre-KTx donor BKV-seroreactivity and occurrence of both viremia and PVAN $(p<0.001)$. Pre-KTx BKVseroreactivity of the recipient was not associated. The hazard ratio (HR) of viremia was substantially higher in recipients of high compared to low seroreactive donors (HR 6.92, 95\% CI 3.41-14.06, $p<0.001$ ), and slightly reduced in high seroreactive recipients (HR $0.57,95 \%$ CI $0.33-0.98, p=0.041$ ). In univariate analysis, donor seroreactivity was the strongest baseline factor associated with viremia post-KTx $(p<0.001)$ outcompeting other described risk factors. Multivariate analysis revealed the same picture and moreover indicated a protective effect of recipient BKV-seroreactivity before KTx. Stratified analysis showed that the hazard of high donor seroreactivity further increased in low BKV-seroreactive recipients.

Conclusions: A strong association was observed between donor BKV-seroresponse and recipient BKV-viremia and PVAN, which surpassed any other association observed in this large living kidney transplant cohort. This observation points directly to the 
donated kidney as the source of BKV-induced disease in KTx recipients and suggests a close relationship between measured BKV-seroreactivity and donor infectious potential, possibly reflecting the BKV kidney graft load. Altogether, our findings warrant further research into the usefulness of BKV-serological donor testing prior to transplantation, in order to predict BKV-infection in the recipient.

\section{http://dx.doi.org/10.1016/j.jcv.2015.07.051}

\section{Abstract No: 1446}

Presentation at ESCV 2015: Oral 42 Subclass specific antibody responses to HCMV in transplant recipients and their association with constant heavy IgG chain polymorphism and virus replication

S. Benedikt*, L. Weseslindtner, I. Görzer, K. Pollak, E. Puchhammer-Stöckl

Department of Virology, Medical University Vienna, Austria

Background: Human cytomegalovirus (HCMV) causes severe infections in transplant recipients. The significance of the HCMVspecific antibody $(A B)$ response in limiting HCMV replication is so far not entirely clear. In the present study we therefore analysed the HCMV-specific subclass $A B$ profile in lung transplant recipients (LTRs) and its association with HCMV-DNAemia. In addition, we have analyzed its association with the patients allotypes GM3 and GM17, which are expressed at the $\mathrm{CH} 1$ region of the constant $y 1$ heavy chain, and differ by single genetic variations, mainly by the single nucleotide polymorphism (SNP) rs1071803 (359 a/g nucleotide variation).

Methods: We determined HCMV-specific total IgG, IgG1 and IgG3 AB levels by ELISA and HCMV-DNAemia by quantitative PCR during the post-transplant follow-up in 57 LTRs, and in 44 of these the GM 359a/g variant (GM3/17) was determined by genotyping.

Results: In seropositive LTRs HCMV ABs increased with HCMV viremia $(p=0.0005)$, and this was significantly associated with development of low level DNAemia ( $<1000$ copies $/ \mathrm{ml}: p=0.0012$; DNAemia $>1000$ copies/ml: $p=0.0516)$. Only IgG3 but no IgG1 increase was observed with viremia (IgG3: $p=0.0004)$. IgG1 levels were significantly lower in patients with the $359 \mathrm{~g} / \mathrm{g}(\mathrm{GM} 3 / 3)$ than in those with the 359a/g (GM3/17) variant $(p<0.0001)$. The $\operatorname{IgG3}$ increase with viremia was significant especially in patients carrying the IgG1 low level $359 \mathrm{~g} / \mathrm{g}$ variant $(p<0.0002)$.

Conclusions: The present data suggest that the HCMV specific $A B$ response significantly contributes to limit HCMV replication after transplantation and provide evidence that the patients GM 3/17 variant is significantly associated with their HCMV IgG subclass profile.

http://dx.doi.org/10.1016/j.jcv.2015.07.052
Abstract No: 1477

Presentation at ESCV 2015: Oral 43

Measles elimination in the World Health

Organization European Region in light of recent outbreaks: Spotlight on the Balkans

J.M. Hübschen ${ }^{1, *}$, I. Salimovic-Bešic ${ }^{2,1}$, A. Dedeic-Ljubovic $^{2,1}$, S. Rakic Adrovic ${ }^{3,1}$, A. Sausy ${ }^{1}$, C.P. Muller ${ }^{1}$

${ }^{1}$ Department of Immunology, Luxembourg Institute of Health/Laboratoire National de Santé, Esch-Sur-Alzette, France

${ }^{2}$ University Clinical Centre - Sarajevo, Department for Clinical Microbiology, Sarajevo, BiH, Bosnia and Herzegovina

${ }^{3}$ Institute of Virology, Vaccine and Sera "Torlak", Belgrade, Serbia

Background: The World Health Organization European Region (WHO-EURO) has adopted the goal to eliminate measles by 2015 , but in light of current case numbers and epidemics it is clear that this target will not be met. Elimination is defined on a country level as the absence of endemic cases for at least 12 months. To interrupt endemic transmission, a very high vaccination coverage overall in the country but also in the different regions and cohorts is required. The WHO- EURO region is very heterogeneous and has a multiplicity of challenges and problems. In 2014, more than 16,000 measles cases were registered in WHO-EURO and outbreaks were reported from many different countries including Bosnia and Herzegovina and Serbia.

Methods: The currently ongoing outbreaks in Bosnia and Herzegovina and in Serbia are investigated combining clinical, epidemiological and laboratory data. The mainly affected cohorts are identified and special emphasis is placed on differences in outbreak causes and patterns and virus exportations from the Balkans to other countries within and outside of WHO-EURO.

Results: The results of the outbreak investigations are used as a basis to discuss current challenges and threats to the WHOEURO measles elimination goal such as migrant populations, anti-vaccination groups, vaccination gaps resulting from political instability or inadequate planning, insufficient routine immunization coverage, lack of political and financial commitment, etc.

Conclusion: To achieve measles elimination in the WHO- EURO region, each country has to address its specific problems and challenges, identify and immunize susceptible population groups, react quickly and efficiently in outbreak situations, and renew and reenforce its commitment to attain the elimination goal.

http://dx.doi.org/10.1016/j.jcv.2015.07.053 